\title{
Preparedness for Disaster Risk Management (DRM), Case Studies: Kelantan Flood, Malaysia
}

\author{
Mohd Sayuti Hassan \\ Center for Global Sustainability Studies (CGSS), \\ Universiti Sains Malaysia, Main Campus \\ Murshidah Abdul Jaffar \\ Center for Global Sustainability Studies (CGSS), \\ Universiti Sains Malaysia, Main Campus \\ Shahad Khaldoon Abdulameer \\ Center for Global Sustainability Studies (CGSS), \\ Universiti Sains Malaysia, Main Campus \\ Siti Fairuz Mohd Radzi \\ Center for Global Sustainability Studies (CGSS), \\ Universiti Sains Malaysia, Main Campus \\ Vishanthini A/P Kanasan \\ Center for Global Sustainability Studies (CGSS), \\ Universiti Sains Malaysia, Main Campus
}

\begin{abstract}
In accordance to the massive flash floods that hit Eastern part of Malaysia, which is mostly Kelantan state, a conference was held to explore ideas and sustainable solutions for the disaster. This paper describes one output of the five pillars of disaster management cycle that is "Preparedness" in Disaster Risk Management for Sustainable Development (DRM-SD) model, which was developed by Centre for Global Sustainability Studies (CGSS) Universiti Sains Malaysia (USM). The purpose is to come out with possible solutions and steps to be taken to mitigate the flood disaster while preparing for any possibilities. The method used for the conference is The Town Hall-World Café concept. Over 225 possible solutions are produced in two days in which the conference is conducted. Included in this paper are the recommendations that were found and the organizations which are responsible for the act.
\end{abstract}

Keywords: Preparedness; sustainable development; flood disaster; World Café; sustainable solution. 


\section{INTRODUCTION}

Flood happens nearly every year during monsoon season from late November till March. Since then, it has been a worrying issue for the Malaysians. It has become the most common disaster in Malaysia. Flooding in Malaysia is most probably due to the cyclical monsoon during wet season that happens in Malaysia due to our geographical location (Ibrahim, K. K., 2013).

Flood disaster that happened in 2014 in Kelantan created collaboration between USM, UMK, Federal Development Department of Kelantan (JPPK) and the States Secretary Office of Kelantan (SUK) to organize a stakeholder meeting that was called Kelantan Flood Disaster Management Conference 2015.

The main issues presented and discussed at the conference related to the flooding that happened and the various ways to solve the problem. The conference topics were based on Disaster Risk Management for Sustainable Development (DRMSD) model. In this model there are five main disaster risk management pillars namely prevention, preparedness, response, recovery and governance. DRMSD model is developed by the Centre for Global Sustainability Studies (CGSS), USM (Ibrahim et al., 2013).

\section{METHODOLOGY}

Universiti Sains Malaysia had organized a post-flood disaster recovery conference USM/CGSS in Kelantan (14-16 Feb 2015) on disaster risk reduction and Centre's on-going focus on disaster risk management for sustainable development (DRM-SD). It is true that all vulnerable communities are at risk when faced with hazards and it is this risk that gets realized as disaster eventually; the flood disaster in Kelantan being no different. A number of win-win and no-regret early interventions can reduce risk to an acceptable level with correspondingly reduced disaster impacts making recovery faster and losses bearable. This would involve the vulnerable communities as active participants in the risk reduction process than remain as passive victims. Such disaster risk reduction depends on well-coordinated governance mechanisms across sectors and at all levels.

A meeting was held to assemble 500 members from Government Ministries, offices, private area, Institute of Higher Learning, government offices, media columnists and non-administrative associations (NGOs) in which it gave a chance to them to contribute thoughts on deluge debacle management. The Town Hall-World Café idea was utilized for the exchange. The Town Hall World Cafe method means that there would be exactly five tables each regarded as World Cafes. Members were partitioned into five gatherings and they would move starting with one World Café then onto the next as each of the cafes were allotted to talk about on only one specific component contained in the Disaster Risk Management for Sustainable Development (DRM-SD) model, be it prevention, preparedness, response, recovery or governance. Every one of the members would have the chance to contribute their thoughts in every component as they move between the cafes. Every cafe would be taken care of by a facilitator who is a specialist for the component of the cafe appointed to them. The facilitator was capable to ensure the members centered their thoughts to the separate component at the World Café. 


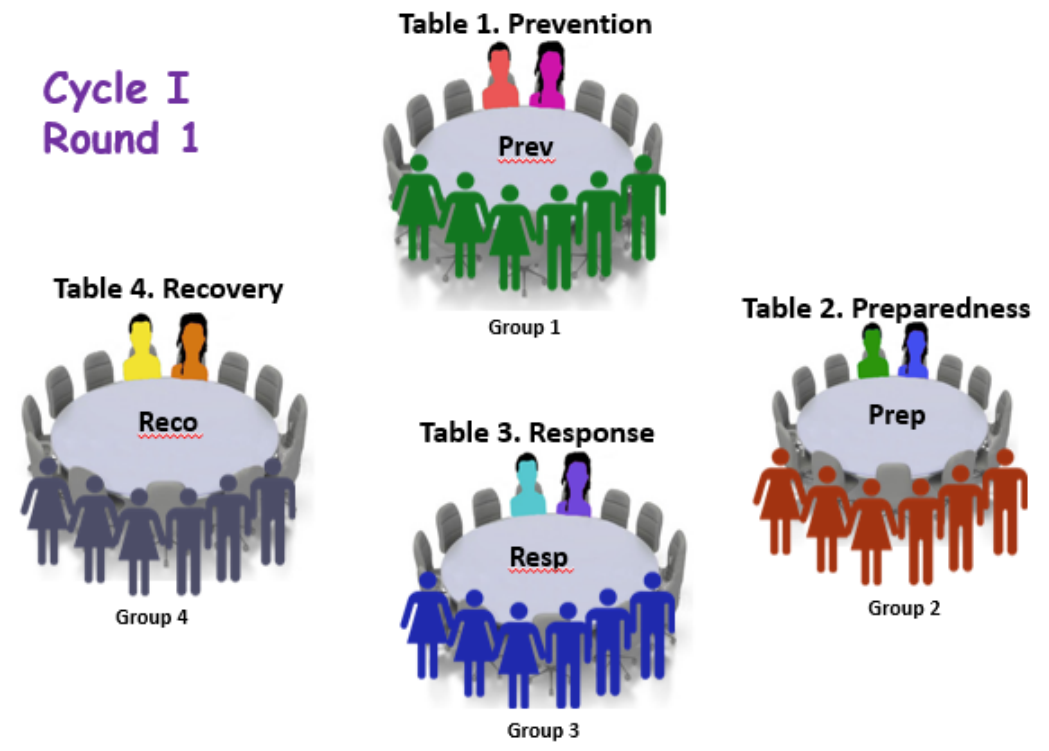

Figure 1. World Café Discussion Method Round1.

The World Café method is designed to create a safe, friendly environment in which to intentionally connect multiple ideas and perspectives on a topic by engaging participants in several rounds of small-group conversation. The use of this method was mainly to explore participants to multiple perspectives of Risk Management for Sustainable Development (DRM-SD) model. Since DRM-SD model content four_elements, therefore, four groupsre we formed. Each of the four groups was distributed to café (table with the specific topic) as in Figure 1. This figure also shows the first round of discussion will take 60 minutes, where, the first 20 minutes, the facilitator in charge on a café briefed the group members on their topic as well as explaining that there will be five rounds for each group with 30 minutes of discussion.

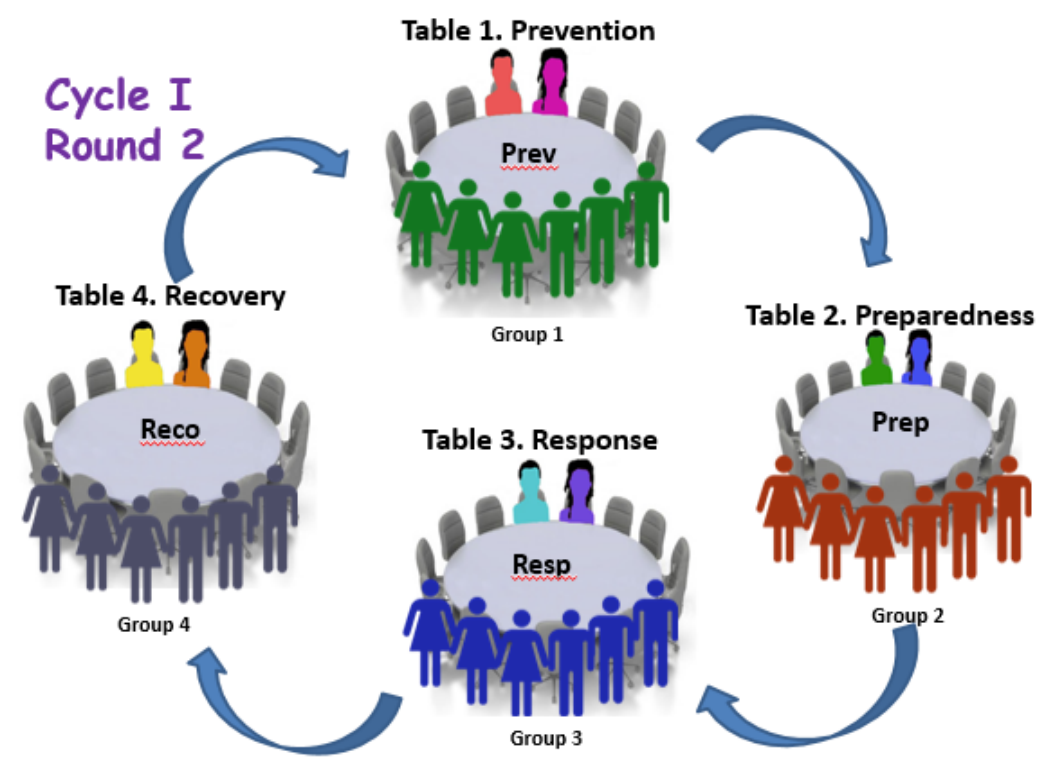

Figure 2. World Café Discussion Method Round 2 
Each group had to move to another café after the first round of discussion. Figure 2 shows the second round, which took 40 minutes, the first 10 minutes were divided between groups movement to their second café, like group one moved from café prevention to café preparedness, group two moved to café Response, while group three moved to café Recovery and finally group four moved to café Prevention, coupled with briefing about the new café topic by their new facilitator. As for the discussion took only 30 minutes.

\section{BACKGROUND}

Beryl, M. (2014) stated that the flood management governance structures vary with geography, population size, infrastructure type, historical district legislation, and public policy. Khalid and Shafiai (2011) highlighted that the disaster management in Malaysia has three levels and every committee in every level has its own responsibility - Level I - the committee ensures coordinated actions, with sufficient asset and human resources, in relation to the media, Level II, must provide to the District assistance such as financial aid, assets and human resources, and Level III, the committee must determine the national disaster management policy, finance, assets and human resources. Activation of the specific executing committee will depend on the characteristics and scale of event as well as coverage of impacted areas (Abdul Wahab, 2011). In Malaysia, disaster management is almost entirely based on a top-down approach. At the very top is the National Disaster Management Risk Centre (NDMRC) running a National Crisis and Disaster Management Mechanism (NCDMM) (Chan 2015). According to Chia (2004), this machinery was established with the objective of co-coordinating relief operations at the federal, state and district levels so that assistance can be provided to flood victims in an orderly and effective manner. The flooding that occurred in late December 2014 was an unprecedented act of nature that displaced hundreds of thousands of Malaysians not just in the flood-prone northern states of the peninsular but also in the south and as far as Sarawak. Chan (1995) stated that it has been estimated that 70\% of the kampungs (villages) in Kelantan, or nearly half of the state's population, were affected. Currently, in the end of December 2014, Eastern Malaysia state, especially Kelantan experience serious flooding which had a negative impact on several states especially on the economy and society in general. Azlee (2015) stated that the National Security Council (NSC) confirmed the massive flood that hit Kelantan was the worst in the history of the state and its secretary Datuk Mohamed Thajudeen Abdul Wahab said water levels of the recent floods superseded the floods of 1967.

The focus of preparedness phase has been generally on moves that states can take on activities by government organizations along with non-governmental organizations (NGOs), neighborhood groups, families, and people. The presumption is that negative impacts of disasters can be diminished through preparation (Hansson et al., 2006). Much exertion has gone into getting individuals to be well prepared and informed about the places that are prone to flooding so that they could take measures to withstand the effects afterwards. Folks are always said to have a special attachment of feelings for places, this is called "place attachment" (Low, 1992). This kind of attachment might disturb the act of preparedness along with evacuation process. It is best for not developing this kind of feelings towards places. That act of preparedness would be on the people themselves. Now, moving on to the Kelantan Flood Disaster Management Conference 2015, there were a plenty of other steps recommended and discussed during the conference in order to have better preparation for the flood that might happen anytime. 
Hassan, M. S., Jaffar, M. A., Abdulameer, S. K., Radzi, S. F. M., \& Janasan, V. A. P. (2020) Preparedness for Disaster Risk Management (DRM), Case Studies: Kelantan Flood, Malaysia. Advances in Social Sciences Research Journal, 7(5) 382-392.

Cambodia, Lao PDR, Thailand and Viet Nam, had implemented Flood Management and Mitigation program to reduce the impact of flooding caused by Mekong River (Perwaiz, 2008). Flood preparedness programme core element of the FMMP resulted in positive relation, remarkably in encouraging sustainability and ownership of the program and in initiating mainstreaming of Flood Risk Reduction (FRR). It emphasised on capacity building, knowledge sharing and public awareness campaigns at provincial, district and community levels, by encompassing five main components: 1) establishment of the regional Centre, 2) structural measurement and flood proofing, 3) mediation of transboundary flood issues, 4) flood emergency management strengthening, 5) land management. In Central Europe (Germany, Austria, the Czech Republic and Slovakia), severe flooding happened in August 2002(Thieken et al., 2007). The household preparedness was lower than $30 \%$ who took no precautionary measures before the flood event, while only $26 \%$ of all households knew how to react to the flooding event (Kreibich, H., 2011). Implementing the Flood Risk Management helped to reduce unprepared householders to $10 \%$ only during 2006 flooding, by focusing on three features: (a) flood regression, with the aim to avoid peak flows, (b) flood control, aimed at preventing inundation by means of structural measures, e.g. embankments or detention areas; and (c) flood alleviation with the goal of reducing flood impacts by non-structural measures (Parker, 2000). The last can be classified into precautionary and preparative measures. Precaution and preparation help to limit and manage the adverse effects of a catastrophe, and to build up coping capacities by flood-resilient design and construction, development of early warning systems, insurance, awareness campaigns, education, training, putting rescue units on stand-by, which help to reduce unpreparedness among the householders (Thieken et al., 2007). But also this method had its limitation as it only implements for the householder not including the businesses (Kreibich, H., 2011).

\section{FINDING}

One of the most important findings from that discussion is all stakeholders and the National Security Council are urged to provide latest databases about flood information to the staff who works under them that are responsible for it. This is to make sure all staff carryout surveillances on the weather and monsoon changes. Latest technology is definitely more than possible in today's rapidly developing world. Therefore, a little upgrade on technology is always in favor for us. Remote Sensing is one of the technologies mentioned. It is a very effective way in providing synoptic coverage over a wider area and very cost effective. In the upgraded version of this technology exist a tool of monitoring the change or reconstruct progress of past flood (Sanyal et al., 2004).

Ministry of Communications and Multimedia Malaysia along with Telecommunication companies should join forces in times like this to upgrade the networking for the sake of improved communication. The step that they could take is by expanding the Government Integrated Radio Networking (GIRN) coverage. Expanding radio networking is a wise step to do since communication is very important in the course of natural hazards (Ibrahim et al., 2013). Better communication reduces effects. Ministry of Finance should come up with budget allocation for implementation of these measures especially for areas that are prone to floods.

After expanding the coverage, these companies should now build electrical substations in appropriate area. The substations should only be developed in that particular area after analyzing the area carefully (Sanyal et al., 2004). This is to ensure that electrical substations are not built in rural area without any residents residing. Living has become so much easier due to the developing 
technology (Jeyaseelan, 2002). We now can even charge our phone without the need to search for direct current supply. In times of disaster, power banks stock supply should be provided for mobile phone in terms of communication purposes. For this, the availability of power banks should be ensured by the company and Federal Government. Power banks should be provided to the workers at the evacuation centres to exchange information from headquarters and also the evacuation centre. The public should also be provided with one but the workers or the volunteers should be prioritized. Other relevant equipment should also be enhanced and revised their specifications and capacities to suit the flooding disaster. Another crucial step that needs to be taken by Tenaga Nasional Berhad is to provide every district prone to flooding with a stand-alone electrical generator. The generator capacities should just be enough to dispense adequate power to meet the necessity.

During flooding season, people still have to eat and continue their lives. Therefore, adequate food supplies are needed. In order to prepare for flooding season, food supply is one of the main worrying factors. There are babies and kids who need to be fed on time. Food supply should be collected and gathered at flood evacuation sites. Food allocation sites purposely should be built on higher grounds to prevent water to reach the evacuation sites and destroy them too. All stakeholders can come up with initiatives like generating a coupon system for food distribution together with basic needs distribution. This storage should be built at flood evacuation centres. People are vulnerable to starvation if they do not have enough supply of food (Blaikie, 2014). Water is equally important as food. Getting clean water for drinking and cooking is the major problem during flooding. Therefore, to avoid that kind of sticky and unappealing situation, local authorities and Department of Environment should work together in order to prepare extra water tanks to hold clean water as a preparation to face floods. The water is to meet the consumer or the flash flood victim demands. This is because at times like that, they will be in need of clean water that can be consumed. When there is clean water provided, safety measures should be practiced in a way that water is only used for crucial purposes and are not wasted arbitrarily. There should be a government officer who is assigned to monitor this action to preserve clean water during flooding season. The first action that should be taken after adverse weather conjecture is shipping the bottled water stocks to the evacuation centres (Ibrahim et al., 2013). This should be done right after the weather forecast by the Meteorological Department. District and Land Office who are responsible for this matter should always monitor weather forecasts.

Monitoring water quality is very important in food preparation. Water sample should always be monitored and warning system should be developed at the permanent sampling sites. Water sampling process is to supervise the quality of water from time to time. Hydrologists found difficulty in coping with water quality problems. This is indeed because there are not many studies and surveys regarding this area carried out by earlier scientists and hydrologists. Then, the joint of UNESCO/WHO publication Water Quality Surveys (1978) intended to synthesize the assessments of the hydrological regime and quality changes brought about by nature (flood) and man (Keith, 2008).

Since water quality drops during flooding season and consuming it could be harmful to human, therefore this act is very vital. Other than that, river should be taken care too. River improvement is also needed since flooding is mostly caused by overflow of river water. As for Natural River, there is always room for improvement. The same goes for man-made river that can be improved in order 
Hassan, M. S., Jaffar, M. A., Abdulameer, S. K., Radzi, S. F. M., \& Janasan, V. A. P. (2020) Preparedness for Disaster Risk Management (DRM), Case Studies: Kelantan Flood, Malaysia. Advances in Social Sciences Research Journal, 7(5) 382-392.

to let the flood water flow through them. Monsoon season which is also known as wet season causes heavy rain almost every day. When rain water flows through mountains, most probably landslide will occur. As a preparation measure, warning system for landslides should be provided to avoid any unforeseen circumstances (Keith, 2008). It is always better to expect the unexpected. These actions should be best taken into responsibilities of the Department of Irrigation and Drainage, Department of Environment, and also Malaysian Public Works Department. As for the nonwaterproof property, it is best to move them to a higher ground. In that way, they will not be damaged. The non-waterproof property include books, wood furniture, electronic devices like mobile phone, laptop and few other important and valuable electronic products, and clothing. If there is a warning for flash flood, the masses should start to prepare all of these things before it is too late.

Because of flood water, many areas and roads might be affected and damaged to certain point, therefore, the responsible parties should install road block and opened other alternative roads for the people to use in case of emergency. Operator who is in charge should assist them whenever they need it. Malaysian Road Transport Department along with Police Department should join forces to make it happen. This is also a way of preparing to face the flood that could happen anytime especially at the disaster prone area (Ibrahim et al., 2013).

As for the safe areas that will not be affected by the floods, Defense Department and Ministry of Defense will have to provide every day basic facilities. These basic necessities are needed for the victims and also people living in those area to use it in times of the monsoon season. Just like nonwaterproof properties, valuable assets will also need to be transferred to higher grounds. The transferred assets should be also secured to avoid unexpected situations to happen.

In order to prepare for the upcoming flood, the people should be briefed about the health and safety measures. This is significant because the victims should know what steps they should take and also the prohibitions that exist. This briefing session can also be executed at the respective evacuation centers in the midst of the disaster. All evacuation centres need to be identified by the Department of Social Welfare to ensure the food, water and other basic necessities are sent over there.

We also did a study regarding the preparedness when the flood happened. The scope of the study was limited to get information about their knowledge, practice, flood preparedness, and flood response. The area of the study consisted of six villages including Kampung Kemerok, Pantai Sabak, Pengkalan Chepa; Kampung Wakaf Aik, Bachok; Kampung Pulau Gajah, Bachok; Kampung Pulau Pisang, Kedai Buluh; Kampung Pulau Pak Amat, Pantai Cahaya Bulan; and Kampung Padang Jambu, Pantai Cahaya Bulan. Fifty respondents from each village were selected for the study, making a total of 300 respondents.

This study used two methodologies, namely the qualitative method and the quantitative method. The qualitative research focused on meanings, traits, and characteristics of events, people, interactions, settings or cultures, and experiences. According to Richard (2009), a leading proponent of qualitative method, aspects of quality are issues related to the what, how, when, and where of a thing; including its essence and ambience. Qualitative research thus refers to the "meanings, concepts, definitions, characteristics, metaphors, symbols, and descriptions of things" 
(Berg, 2007). From each village, 10 stakeholders were interviewed, making altogether 60 stakeholders from six villages.

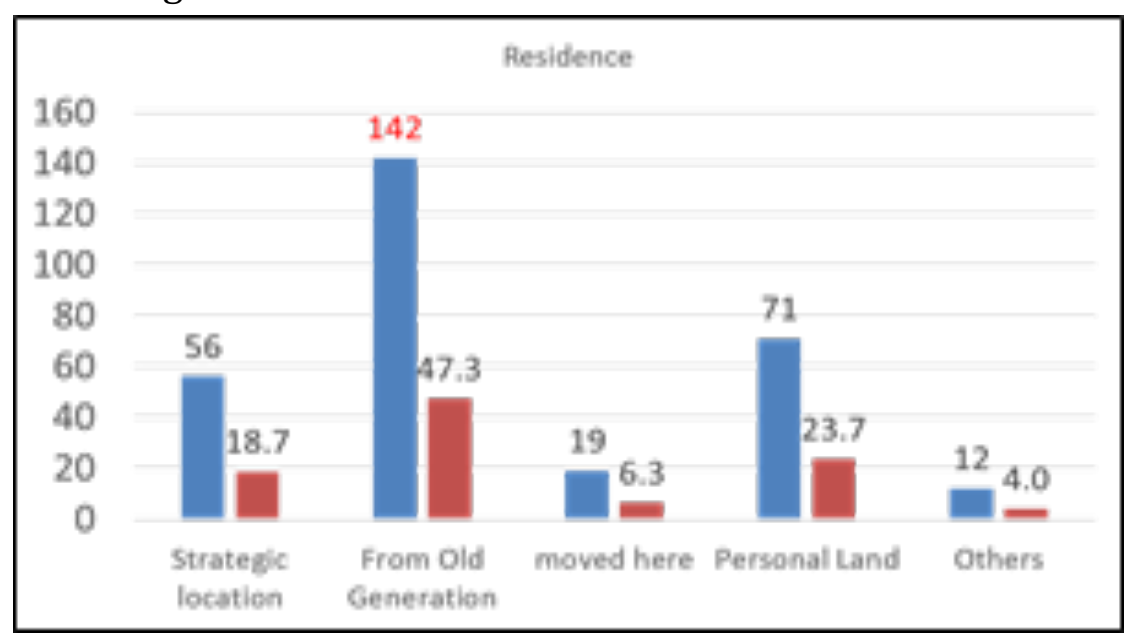

Figure 3. Communities living in coastal areas

Figure 3 shows that most of the communities (47.3\%) live in the coastal areas because they have stayed there for many generations. Then, $23.7 \%$ of the respondents lived there because they stayed on their own personal land. Another $18.7 \%$ said that they stayed there because the location is very strategic. Finally, $6.3 \%$ of the respondents said they moved to that area. Clearly, $81.3 \%$ of these communities living in the coastal areas due to place attachment syndrome, while $18.7 \%$ were affected by life requirement.

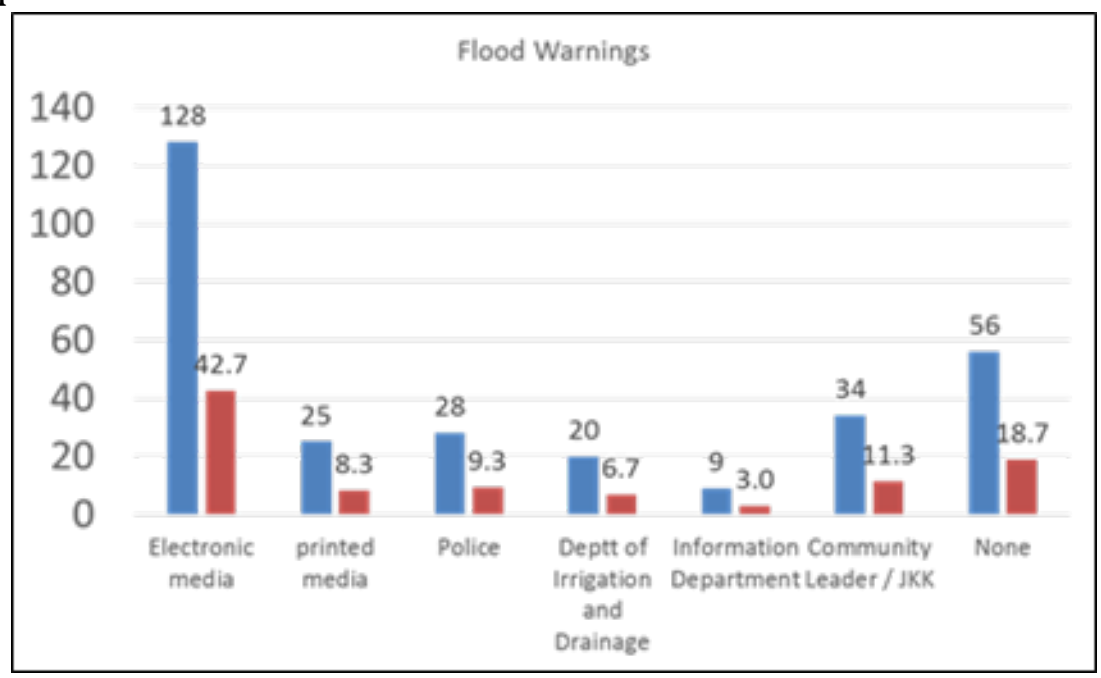

Figure 4. Flood information

Figure 4 shows that $42.7 \%$ of the sample received information regarding flood from electronic media, $11.30 \%$ from JKKK, $9.30 \%$ from police, $8.3 \%$ from printed media, and $6.7 \%$ from the Department of Irrigation and Drainage. After all, only $49 \%$ of the residence had been notified by governmental departments while the rest $51 \%$ depend on the different types of media.

Figure 5 shows that $44.67 \%$ of the respondents knew about flooding. A flood is an annual event for them, but the 2014 flood was none like previous floods. Furthermore, 29.67\% of respondents 
Hassan, M. S., Jaffar, M. A., Abdulameer, S. K., Radzi, S. F. M., \& Janasan, V. A. P. (2020) Preparedness for Disaster Risk Management (DRM), Case Studies: Kelantan Flood, Malaysia. Advances in Social Sciences Research Journal, 7(5) 382-392.

answered they were not sure with their knowledge on the flood, $9.67 \%$ said they have a good knowledge, 9.00\% had few knowledge and the remaining $6.67 \%$ had no knowledge about the flood. It seems, only $54.34 \%$ of the residences had awareness about the safety procedures. while $45.66 \%$ of the residents where lack of knowledge related to safety procedures.

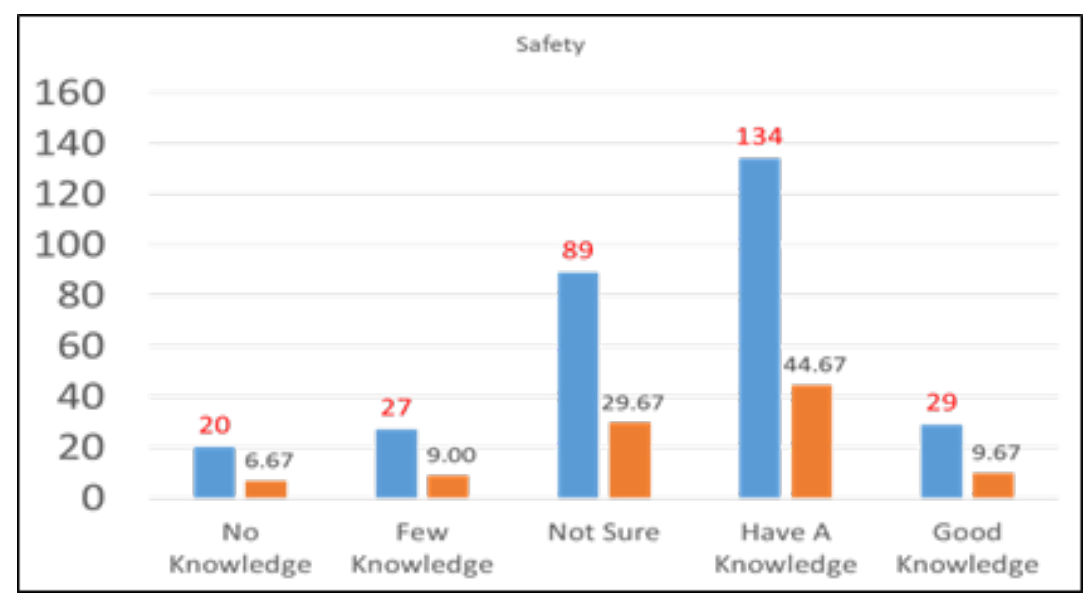

Figure 5. Safety knowledge

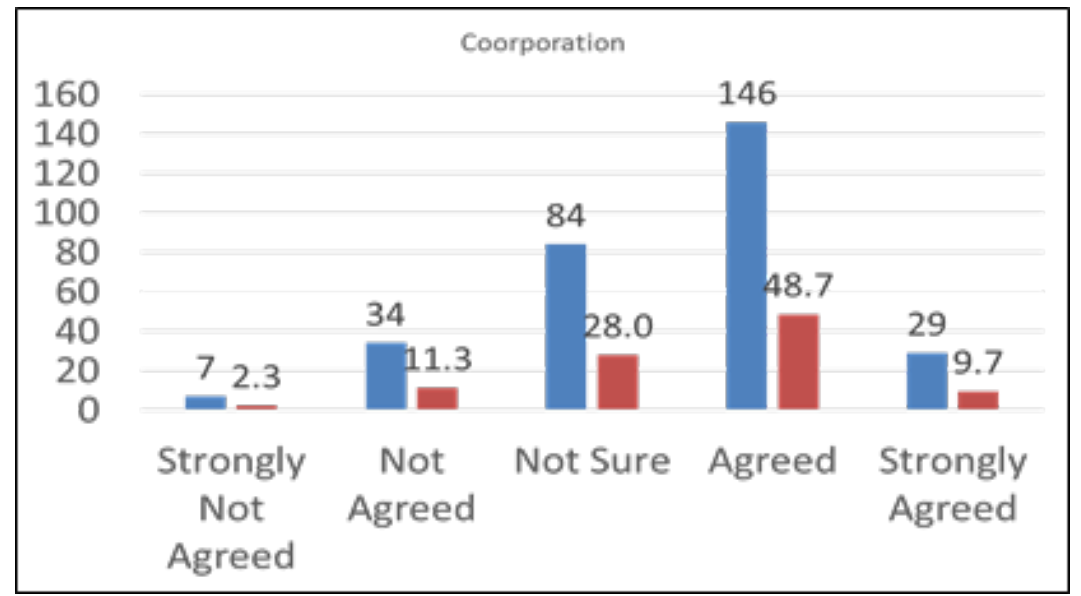

Figure 6. The importance of cooperating

Figure 6 shows the result of the questionnaire on the residents' agreement to the statement "Possess knowledge on the importance of cooperating with each other to solve flood issue." On this response, $48.7 \%$ of them said they agree with the statement, $28.0 \%$ respondents were not sure, $11.30 \%$ did not agree, $9.7 \%$ strongly agreed and the remaining $2.3 \%$ strongly disagreed. In another word, $58.4 \%$ of the residents' positive knowledge of the importance of the cooperation in solving flooding issue, whereas, $28 \%$ and $13.6 \%$ were uncertain and reject the importance of cooperation, respectively.

Table 1. Preparation to Face Flood

\begin{tabular}{|c|c|c|}
\hline Items & Frequency & \% \\
\hline Store enough food & 55 & 18.33 \\
\hline Keep important documents in a secured place & 48 & 16.00 \\
\hline Cautious during heavy rainfall & 38 & 12.67 \\
\hline Keep belongings and vehicles at a safe place/location & 30 & 10.00 \\
\hline
\end{tabular}


Table 1 shows that $18.33 \%$ respondents stored enough food before flood occurred, $16.00 \%$ focused on keeping important documents at a secure place, $12.67 \%$ said they stayed cautious during heavy rainfall and $10.00 \%$ of them said they keep their belongings and vehicles at a safe place or location as a preparation to face flood.

Table 2. When Flood Occurs

\begin{tabular}{|c|c|c|}
\hline Items & Frequency & \% \\
\hline Move to a safe place & 76 & 25.33 \\
\hline Take care of the safety of family and own self & 34 & 11.33 \\
\hline Listen and follow orders from the authority & 26 & 8.67 \\
\hline Take care of the safety and health & 24 & 8.00 \\
\hline Save family members & 20 & 6.67 \\
\hline
\end{tabular}

Table 2 shows that when flood occurs, $25.33 \%$ of the respondents said they would move to a safe place, $11.33 \%$ said they would ensure the safety of the family and their own self, $8.67 \%$ listened and followed orders from the authority, $8.00 \%$ took care of the safety and health, and lastly, $6.67 \%$ said they would save family members first.

\section{CONCLUSION}

The principle point of urban flood risk management is to minimize human misfortune and monetary harms. Flood dangers cannot be totally maintained from a strategic distance; in this manner they must be overseen. Hence, flood management does not endeavor to wipe out flood hazard but rather to mitigate them. Disaster risk management activities have concentrated on danger recognition and management, arranging or absence of in building in danger inclined territories, proper areas and development strategies if individuals choose to live in high-chance zones, evasion, deferral and moderation of impacts, building of protections and fortresses, safe houses and shelters, procurement of data, notices and requests, clearing potential outcomes, modes, arranges, and penetrates, and readiness for catastrophes(Lewis \& Kelman, 2009). However, not everyone avoids high-risk areas. This may be due to things that are inevitable like finance problem or other circumstances. Therefore, preparedness efforts should be taken by various agencies to face flooding season. Disaster preparation is crucial especially to those states prone to natural disasters.

\section{Acknowledment}

The authors would like to thank to FRGS Grant, Ministry Of Higher Education Malaysia (Research Title : Governance for disaster risk reduction: Integrated Governance Approaches to Flood Disaster Management in Malaysia using Risk Reduction Tools Leading to Sustainable Development - Project Code : 6711481) for financial support. Authors are also grateful to the anonymous reviewers for their insightful suggestions and careful reading of the manuscript.

\section{References}

Abdul Wahab, M.T. (2011). National Progress Report on the Implementation of the Hyogo Framework for Action (2009-2011), Malaysia.

Azlee, A. (2015). Worst Floods In Kelantan, Confirms NSC, Malaymail.

Berg, Bruce. (2007). Qualitative Research Methods for the Social Sciences (6th Ed). Boston: Pearson Education. Beryl, M. (2014). Yolo County Flood Governance Study. University Of California, Davis. 
Hassan, M. S., Jaffar, M. A., Abdulameer, S. K., Radzi, S. F. M., \& Janasan, V. A. P. (2020) Preparedness for Disaster Risk Management (DRM), Case Studies: Kelantan Flood, Malaysia. Advances in Social Sciences Research Journal, 7(5) 382-392.

Blaikie, P. C. (2014). At Risk: Natural Hazards, People's Vulnerability And Disasters. Routhledge.

Chan N.W. (1995). Flood Disaster Management in Malaysia: An Evaluation of the Effectiveness of Government Resettlement Schemes. Disaster Prevention and Management, 4(4), 22-29.

Chan, N. W. (2015). Impacts of Disasters and Disaster Risk Management in Malaysia: The Case of Floods. In Resilience and Recovery in Asian Disasters. Springer, Japan. 239-265 pp.

Chia, C. W. (2004). Managing Flood Problems in Malaysia. Buletin Ingenieur, 22, 38-43.

Hansson, K., Danielson, M. \& Ekenberg, L. (2006). A Framework for Evaluation of Flood Management Strategies. Journal of Environmental Management, 86(3), 465-480.

Ibrahim, K., Koshy, K.C., Akib, N.A.M., Nor, R.M., Manaf, N.A., Azhar, S.N F.S. \& Muslim, M. (2015). Resolution Kelantan Flood Disaster Management Conference 2015.

Ibrahim, K. K. (2013). Development with a Difference: Neo-Disaster Risk Management for Sustainable Development. In Geomatics, Natural Hazards and Risk. Taylor \& Francis, London. 1-6 pp.

Jeyaseelan, A. (2002). Droughts \& Floods Assessment and Monitoring Using Remote Sensing and GIS:

Satellite Remote Sensing and GIS Applications in Agricultural Meteorology, Crop Inventory and Drought Assessment Division National Remote Sensing Agency Department of Space, Govt. of India, Hyderabad 291-313.

Keith, H. D. (2008). Disaster Management and Response: A Lifelines Study for the Queenstown Lakes District. Master Thesis, University of Canterbury.

Khalid, M. S. B. \& Shafiai, S. B. (2015). Flood Disaster Management in Malaysia: An Evaluation of the Effectiveness Flood Delivery System. International Journal of Social Science and Humanity, 5(4), 398.

Kreibich, H., Seifert, I., Thieken, A. H., Lindquist, E., Wagner, K. \& Merz, B. (2011): Recent Changes in

Flood Preparedness of Private Households and Businesses in Germany. Regional Environmental

Change, 11(1), 59-71.

Lewis, J. \& Kelman, I. (2009). Housing, Flooding and Risk-Ecology: Thames Estuary South-Shoreland and North Kent. Journal of Architectural and Planning Research, 26(1), 14-29.

Low, S. A. (1992). Place Attachment: A Conceptual Inquiry. New York: Plenum Press.

Parker D.J. (2000a). "Introduction To Floods And Flood Management”. In: Parker, D.J. (Ed.): Floods, Volume I, London \& New York, Pp. 3-39.

Penning-Rowsell, E. C. \& Green, C. (2000). New Insights into the Appraisal of Flood-Alleviation Benefits: (1) Flood Damage and Flood Loss Information. Journal of Charted Institutions for Water Engineers, 14, 347-353.

Perwaiz, A. (2008). Flood Preparedness and Emergency Management People-Centred approach in Integrated Flood Risk Management, Annual Flood Report 2008,MRCS.

Richard (2009), Understanding Why Qualitative Methods Are Superior For Criminology And Criminal Justice: Qualitative Versus Quantitative Methods. Journal of Theoretical and Philosophical Criminology, 1(1), 1-21

Sanyal, J. \& Lu, X. (2004). Application of Remote Sensing In Flood Management with Special Reference to Monsoon Asia: A Review. Natural Hazards, 283-301.

Thieken, A.H.(2007). Coping With Floods: Preparedness, Response and Recovery of Flood-Affected Residents in Germany in 2002. Hydrological Sciences Journal, 52(5), 1016-1037. 